Original Article

\title{
Single-Port vs Conventional Three-Port Video- Assisted Thoracoscopic Pulmonary Wedge Resection: Comparison of Postoperative Pain and Surgical Costs
}

\author{
Yasushi Mizukami, MD, Yuki Takahashi, MD, and Hirofumi Adachi, MD
}

\begin{abstract}
Purpose: Single-port video-assisted thoracoscopic (VATS) pulmonary wedge resection was reported in 2004. We started using single-port VATS (SPVATS) pulmonary wedge resection in 2017 and compared results between conventional three-port VATS (VATS group) and SPVATS (SPVATS group).

Methods: We identified 145 consecutive patients with VATS group and SPVATS group. Perioperative characteristics including pain and the number of stapler cartridges used were examined as the surgical outcomes, retrospectively.

Results: In all, 66 cases of SPVATS group and 79 cases of VATS group pulmonary wedge resection were compared. The rate of epidural anesthesia $(p<0.0001)$ was significantly higher and operative time ( $\mathbf{p}<\mathbf{0 . 0 0 0 1})$ was significantly longer with VATS group than with SPVATS group. The number of stapler cartridges used, duration of drain insertion, and rate of postoperative complications did not differ significantly between groups. Average numerical rating scale (NRS) score on postoperative day 1 and postoperative day 7 $(p<0.0001$ each), maximum NRS score on postoperative day $7(p=0.0082)$ and amount of $25 \mathrm{mg}$ tramadol $(p=\mathbf{0 . 0 0 6 2})$ were significantly lower in SPVAS group than in VATS group. Conclusion: Our results suggest that SPVATS pulmonary wedge resection offers better pain control and cost-effectiveness than three-port VATS pulmonary wedge resection. These findings should contribute to the body of evidence for SPVATS.
\end{abstract}

Keywords: pulmonary wedge resection, single-port video-assisted thoracoscopic surgery, uniportal video-assisted thoracoscopic surgery

Department of Thoracic Surgery, National Hospital Organization, Hokkaido Cancer Center, Sapporo, Hokkaido, Japan

Received: May 21, 2020; Accepted: July 7, 2020

Corresponding author: Yasushi Mizukami, MD. Department of Thoracic Surgery, National Hospital Organization, Hokkaido Cancer Center, 2-3-54 Kikusui 4-jo, Shiroishi-ku, Sapporo, Hokkaido 003-0804, Japan.

Email:mizukam@gmail.com

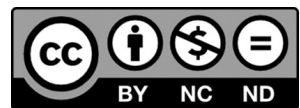

This work is licensed under a Creative Commons Attribution-NonCommercialNoDerivatives International License.

(C)2021 The Editorial Committee of Annals of Thoracic and Cardiovascular Surgery

\section{Introduction}

Single-port video-assisted thoracoscopic (VATS) wedge resection was first reported in 2004. ${ }^{1)}$ Since then, awake single-port VATS has been reported. ${ }^{2)}$ Single-port VATS lobectomy has also been reported recently. ${ }^{3}$ We have been performing single-port thoracoscopic pulmonary wedge resection since 2017, although pulmonary wedge resection has continued to be performed using three ports.

Although conventional three-port VATS requires three incisions and intercostal spaces, single-port VATS requires only a single incision and a single intercostal 
space. Single-port VATS appeared tolerable, safe, and efficient for treating spontaneous pneumothorax in a series we reported. ${ }^{4)}$

Although the literature is growing regarding the reduced burdens on the patient from single-port VATS in terms of postoperative pain, paresthesia, and cost,$^{5)}$ no prospective, randomized trials have been reported comparing singleport VATS to conventional VATS, so the evidence remains insufficient. We therefore compared single-port VATS pulmonary wedge resection with three-port VATS pulmonary wedge resection in terms of pain and cost.

\section{Materials and Methods}

We identified 145 patients who had undergone either three-port pulmonary wedge resection between January 2015 and December 2016 or single-port pulmonary wedge resection between January 2017 and December 2019 (Fig. 1). We had performed only conventional three-port VATS pulmonary wedge resection until 2016, and started to perform single-port VATS pulmonary wedge resection from 2017. We compared a three-port VATS group from 2015 to 2016 with a single-port VATS group from 2017 to 2019. Ethics approval for this study was granted by the ethics committee at Hokkaido Cancer Center (approval number: 31-51); the requirement to obtain informed consent directly was waived and informed consent was obtained in the form of opt-out on the website of our institution. This study retrospectively reviewed the clinical records of patient for data including age, sex, smoking history, intraoperative findings, postoperative findings, pain, and use of analgesics at a single center (Hokkaido Cancer Center, Sapporo, Japan).

Although epidural anesthesia was performed at the discretion of the anesthesiologist, basically during this study the policy of the insertion of epidural anesthesia was to perform in all cases. Epidural anesthesia was not performed due to taking antithrombotic drugs, deformity of thoracic vertebrae, history of vertebrae operation, patients' requests or difficulty of insertion, and so on. Intercostal nerve block was performed intraoperatively if no epidural anesthesia was applied intraoperatively. Both procedures were performed with the patient in the lateral decubitus position under general anesthesia. The trachea was canalized with a double-lumen tube for selective ventilation of the lung. A 3- to 4-cm operator's port was made in front of the anterior line of the latissimus dorsi muscle on the posterolateral incision line (basically within the fourth, fifth, or sixth intercostal space, depending on tumor location)

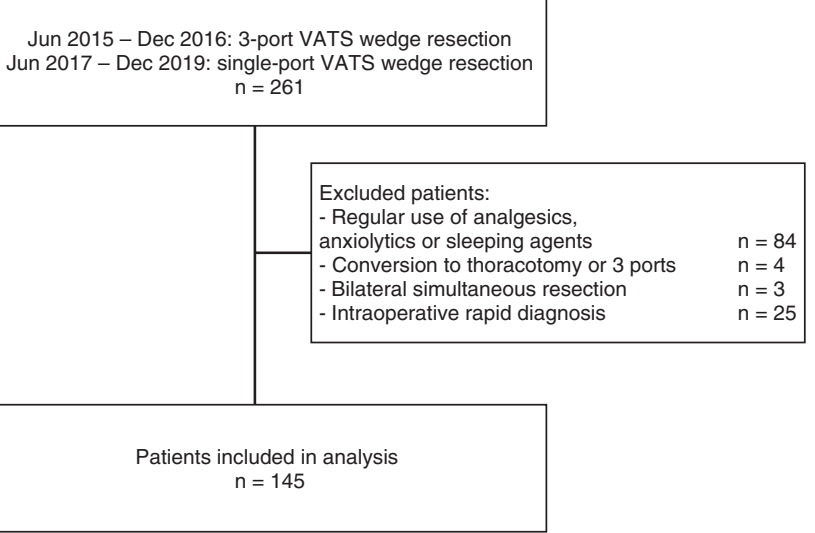

Fig. 1 Flow chart for selection of patients analyzed in this study. VATS: video-assisted thoracoscopic surgery

(Fig. 2). A protective film and ring device for protecting the wound (LAPPROTECTOR; Hakko Co. Ltd., Tokyo, Japan) was used. In single-port VATS, a 5-mm thoracoscope was inserted through the operator's port. In threeport VATS, a 5-mm port for the thoracoscope was inserted in the mid-axillary line (in the sixth intercostal space, at a point that looks down the major fissure, sometimes more caudally). A 2-cm assistant's working port was made at a posterior location on the same line (in the seventh intercostal space) (Fig. 3). All pulmonary nodules were detected by palpation and were resected with sufficient surgical margins. Our policy of surgical margins was to secure a finger breadth (more than $15 \mathrm{~mm}$ ) from the nodule, although it was occasionally difficult to comply with it due to the size of the nodule, the large number of nodules or the location. Linear staplers were $45-$ or $60-\mathrm{mm}$ reload cartridges with the End GIA ultra universal stapler (Medtronic, Minneapolis, MN, USA) or ECHELON FLEX ENDOPATH stapler (Ethicon Inc., Cincinnati, OH, USA). Seven surgeons as an operator participated including three senior surgeons with over 10 years of experience and four resident surgeons less 10 years of experience. Basically, although in early stage single-port VATS for only easy cases were performed by senior surgeons, we become able to do single-port VATS soon and all cases were performed by this procedure. Not only experienced surgeons but also resident surgeons selected single-port VATS.

For postoperative analgesia, continuous intravenous infusion of fentanyl was added on postoperative day 1 . On the same day, oral administration of the non-steroidal anti-inflammatory drug celecoxib was started. If drug allergy or renal dysfunction was present, acetaminophen was used instead. When pain control was insufficient, 


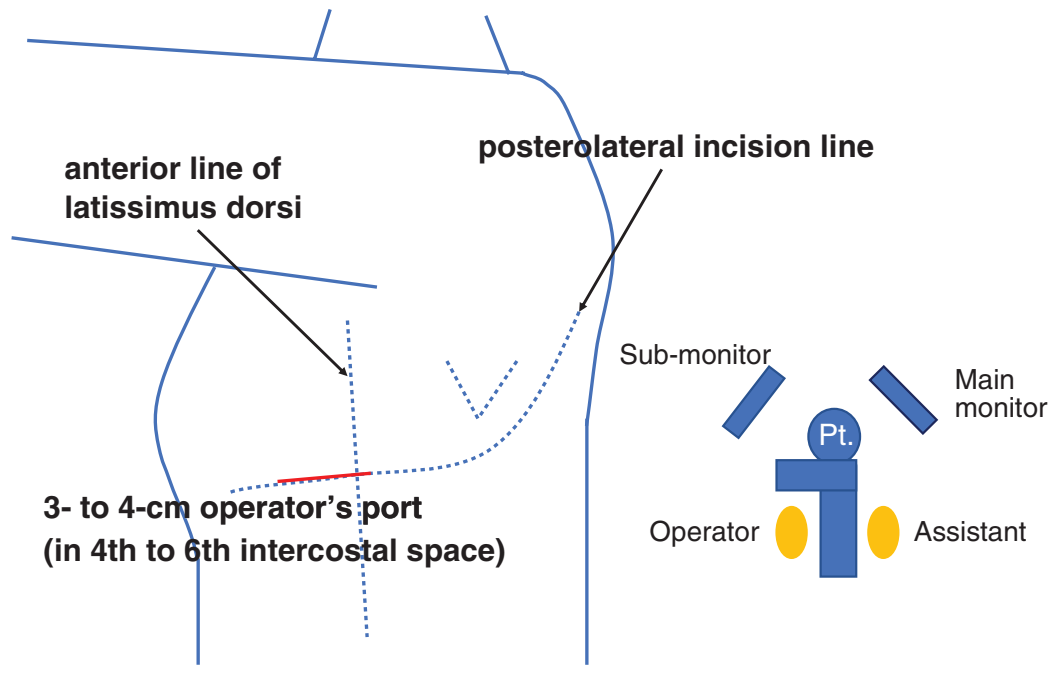

Fig. 2 Port disposition of single-port VATS pulmonary wedge resection (left-side approach). A 3- to 4-cm operator's port is made in front of the anterior line of the latissimus dorsi muscle on the posterolateral incision line (basically in the fourth, fifth, or sixth intercostal space, depending on tumor location). VATS: video-assisted thoracoscopic

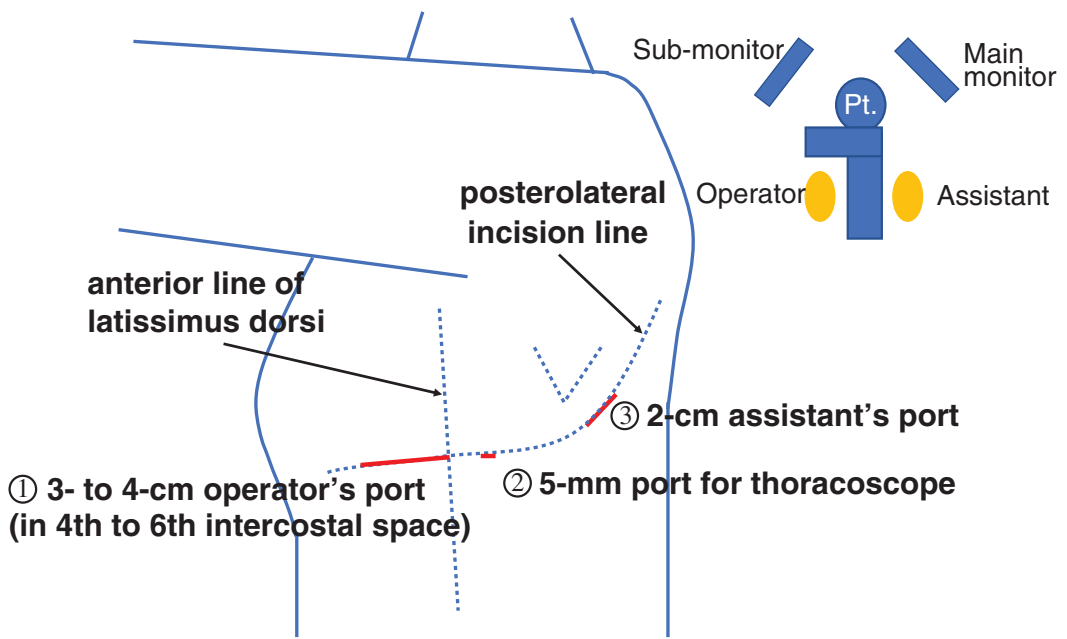

Fig. 3 Port disposition of three-port VATS pulmonary wedge resection (left-side approach). In addition to the operator's port, which was in the same position as in the single-port procedure, A 5-mm port for the thoracoscope is inserted at the mid-axillary line (in the sixth intercostal space, at a point that looks down the major fissure, sometimes more caudally). A 2-cm assistant working port was made at a posterior location on the same line (in the seventh intercostal space). VATS: video-assisted thoracoscopic

tramadol was provided according to patient's request. Rate of pain was assessed using the numerical rating scale (NRS). The date on which patients stopped receiving analgesics was examined.

Continuous variables are summarized as median and range. All statistical analyses were performed using JMP ${ }^{\circledR}$ version 13 (SAS Institute, Cary, NC). Pearson's chi-square test and Student's t-test were used for statistical analyses. Values of $\mathrm{p}<0.05$ were considered significant.

\section{Results}

In all, 66 cases of single-port VATS pulmonary wedge resection and 79 cases of three-port VATS pulmonary 
Table 1 Univariate analysis of preperative patient's characteristics

\begin{tabular}{|c|c|c|c|c|c|c|}
\hline & \multicolumn{3}{|c|}{ Single-port } & \multicolumn{2}{|l|}{3 -port } & \multirow{2}{*}{$\mathrm{p}$} \\
\hline & \multirow[t]{2}{*}{ Total } & \multirow[t]{2}{*}{$\mathrm{n}=65$} & & \multicolumn{2}{|l|}{$\mathrm{n}=82$} & \\
\hline & & & SD & & SD & \\
\hline Age (yr) & & 62 & 19 & 65 & 17 & 0.89 \\
\hline \multirow[t]{2}{*}{ Sex } & Male & $32(49)$ & & $41(50)$ & & \\
\hline & Female & $33(51)$ & & $41(50)$ & & 0.93 \\
\hline BMI (kg/m2) & & 22.6 & 3.3 & 23.0 & 3.5 & 0.55 \\
\hline \multirow[t]{3}{*}{ ASA } & 1 & $7(11)$ & & $3(4)$ & & \\
\hline & 2 & $49(75)$ & & $63(77)$ & & \\
\hline & 3 & $9(14)$ & & $16(19)$ & & 0.18 \\
\hline \multirow[t]{3}{*}{ Smoking } & Never smoker & $24(37)$ & & $32(39)$ & & \\
\hline & Ex-smoker & $35(54)$ & & $46(56)$ & & \\
\hline & Current smoker & $6(9)$ & & $4(5)$ & & 0.58 \\
\hline COPD & & $12(18)$ & & $27(33)$ & & 0.06 \\
\hline Diabetes mellitus & & $11(17)$ & & $11(13)$ & & 0.55 \\
\hline Tumor size (mm) & & 15 & 9 & 16 & 10 & 0.24 \\
\hline \multirow[t]{3}{*}{ CT findings of tumor } & Pure ground glass & $8(12)$ & & $6(7)$ & & \\
\hline & Part solid & $11(17)$ & & $6(7)$ & & \\
\hline & Solid & $46(71)$ & & $70(86)$ & & 0.09 \\
\hline \multirow[t]{2}{*}{ Location of the tumor } & Right & $34(52)$ & & $49(60)$ & & \\
\hline & Left & $31(48)$ & & $33(40)$ & & 0.37 \\
\hline
\end{tabular}

Values represent n (\%), mean. ASA: American Society of Anesthesiologists physical status; BMI: body mass index; CT: computed tomography; COPD: chronic obstructive pulmonary disease

wedge resection were investigated. Patient characteristics and results of endopoints are listed in Tables 1 and $\mathbf{2}$. Univariate analyses were performed. The frequency of epidural anesthesia $(\mathrm{p}<0.0001)$ was significantly higher and operative time $(\mathrm{p}<0.0001)$ was significantly longer in the three-port group than in the single-port group. In cases with epidural anesthesia, average duration of epidural catheterization was 1.1 days in the single-port group and 1.6 days in the three-port group. Pathologically, positive margins were not observed in either group and surgical margin distance was no significant differentiation between two groups. The frequency of patients with sufficient surgical margin distance more than $15 \mathrm{~mm}$ was 54 cases $(93.1 \%)$ of 58 in single-port VATS group and 57 cases $(83.8 \%)$ of 68 in three-port VATS group excluding 19 cases of biopsy for multiple pulmonary nodules. It was no significant differentiation between two groups $(\mathrm{p}=0.11)$.

Number of stapler cartridges, duration of drain insertion, and rate of postoperative complications did not differ significantly between groups. Average NRS on postoperative days 1 and 7 ( $\mathrm{p}<0.0001$ each), maximum NRS on postoperative day $7(\mathrm{p}=0.0082)$, and amount of $25 \mathrm{mg}$ tramadol $(\mathrm{p}=0.0062)$ were significantly lower in the single-port group than in the three-port group.

\section{Discussion}

In this single-center retrospective study comparing single-port VATS pulmonary wedge resection with threeport VATS pulmonary wedge resection, average NRS on postoperative day 1 , average NRS on postoperative day 7 , maximum NRS on postoperative day 7, and amount of 25-mg tramadol were all significantly better in singleport VATS than in three-port VATS.

Pain control by intercostal block is reportedly superior during the first $24 \mathrm{~h}$ after surgery, whereas on the second day after surgery, pain control was significantly better with epidural anesthesia. ${ }^{6}$ ) The frequency of intercostal block was significantly greater with single-port VATS than with intercostal block in three-port VATS, and the period of epidural anesthesia was shorter with single-port VATS than with three-port VATS. These results indicate that single-port VATS pulmonary wedge resection offers better pain control than three-port VATS pulmonary wedge resection.

Several studies have claimed that single-port VATS provides better pain control and better cost-effectiveness than conventional multi-port VATS, such as in pneumothorax ${ }^{4,7)}$ or lobectomy ${ }^{8}{ }^{8}$ However, few reports have looked into single-port VATS wedge resection for pulmonary nodules. 
Table 2 Univariate analysis of results of endopoints

\begin{tabular}{|c|c|c|c|c|c|c|}
\hline & & \multicolumn{2}{|c|}{ Single-port } & \multicolumn{2}{|c|}{ 3-port } & \multirow{2}{*}{$\mathrm{p}$} \\
\hline & \multirow[t]{2}{*}{ Total } & \multirow[t]{2}{*}{$\mathrm{n}=65$} & \multicolumn{3}{|c|}{$\mathrm{n}=82$} & \\
\hline & & & SD & & SD & \\
\hline \multirow[t]{2}{*}{ Analgesia } & Epidural anesthesia & $8(12)$ & & $53(65)$ & & \\
\hline & Intercostal nerve block & $57(88)$ & & $29(35)$ & & $<0.0001$ \\
\hline Operative time (min) & & 65 & 31 & 93 & 39 & $<0.0001$ \\
\hline Intraoperative bleeding (g) & & 3 & 3 & 6 & 17 & 0.1 \\
\hline Intraoperative high adhesion & & $3(5)$ & & $5(6)$ & & 0.73 \\
\hline The number of resection part & & 1.1 & 0.4 & 1.2 & 0.5 & 0.21 \\
\hline $\begin{array}{l}\text { The number of stapler } \\
\text { cartridge used }\end{array}$ & & 4.3 & 1.4 & 3.8 & 1.6 & 0.064 \\
\hline $\begin{array}{l}\text { Length of drain } \\
\text { insertion (days) }\end{array}$ & & 1.2 & 0.9 & 1.5 & 0.8 & 0.1 \\
\hline $\begin{array}{l}\text { Postoperative complication } \\
\text { (CD classification } \geq \mathrm{III})\end{array}$ & & 1 & $\begin{array}{l}\text { (postoperative } \\
\text { pneumothorax) }\end{array}$ & 1 & $\begin{array}{l}\text { (Pleural } \\
\text { effusion) }\end{array}$ & 0.87 \\
\hline Pathological positive margin & & $0(0)$ & & $0(0)$ & & \\
\hline Surgical margin distance (mm) & & 17 & 6 & 16 & 8 & 0.49 \\
\hline \multirow[t]{3}{*}{ Diagnosis } & Lung cancer & $31(47)$ & & $37(45)$ & & \\
\hline & Metastasis & $29(45)$ & & $40(49)$ & & \\
\hline & Other & $5(8)$ & & $5(6)$ & & 0.85 \\
\hline \multirow[t]{3}{*}{ Postoperative day 1} & Average of NRS $\S$ & 0.4 & 0.5 & 0.9 & 0.9 & $<0.0001$ \\
\hline & Max of NRS & 2.5 & 2.1 & 3 & 2.4 & 0.12 \\
\hline & $\begin{array}{l}\text { Amounts of } 25 \mathrm{mg} \\
\text { tramadol (tablets) }\end{array}$ & 0.5 & 0.9 & 0.9 & 1.6 & 0.35 \\
\hline \multirow[t]{3}{*}{ Postoperative day 7} & Average of NRS $\S$ & 0.1 & 0.3 & 0.5 & 0.5 & $<0.0001$ \\
\hline & Max of NRS & 0.5 & 0.7 & 0.9 & 1.1 & 0.015 \\
\hline & $\begin{array}{l}\text { Amounts of } 25 \mathrm{mg} \\
\text { tramadol (tablets) }\end{array}$ & 0.1 & 0.4 & 0.6 & 1.7 & 0.015 \\
\hline
\end{tabular}

Values represent n (\%), mean.CD: Clavien-Dindo; NRS: numerical rating scale

Moreover, evidence for the real benefits and treatment efficacy of whole single-port VATS remains weak. ${ }^{9)}$ Single-port VATS is presumably associated with less pain because only a single intercostal nerve is damaged, compared with multiple intercostal nerves in three-port VATS.

In addition, compared with three-port VATS, singleport VATS shows shorter duration of the operation, use of an equivalent number of stapler cartridges, comparable rates of postoperative complications, and superior perioperative costs compared with three-port VATS. Sufficient surgical margins were secured in the most cases of two groups. The procedure for single-port VATS pulmonary wedge resection is not overly difficult for operators with experience in three-port VATS pulmonary wedge resection. For that reason, the lower the number of ports, the shorter the operation time, while the number of stapler cartridges used and the frequency of postoperative complications remain comparable.

This study had several limitations. First, the procedure we investigated was three-port VATS, and whether our findings are applicable to other multiport VATS procedures such as two- or four-port procedures remains unclear. Second, the operation time in three-port VATS was 30 minutes longer than that in single-port VATS. Except time to open and close incisions, there may be parameters that have not been evaluated to predict that operative time of three-port VATS was longer than that of SPVATS. For example, in this study, whether the interlobar fissure was divided by staplers or whether the intraoperative air leak was repaired were not investigated. These procedures can cause long operation time. Third, this investigation used a single-institution retrospective design, and a multicenter study may be required to further evaluate these issues.

\section{Conclusion}

Our findings suggest that single-port VATS pulmonary wedge resection offers better pain control and cost-effectiveness than three-port VATS pulmonary wedge resection. It is our hope that these findings will contribute to defining a useful body of evidence regarding single-port VATS. 


\section{Acknowledgments}

The authors would like to acknowledge all the staff involved in the care of the patients in the Department of Thoracic Surgery at National Hospital Organization, Hokkaido Cancer Center.

\section{Disclosure Statement}

The authors declare no conflicts of interest associated with this manuscript.

\section{References}

1) Rocco G, Martin-Ucar A, Passera E. Uniportal VATS wedge pulmonary resections. Ann Thorac Surg 2004; 77: 726-8.

2) Rocco G, Romano V, Accardo R, et al. Awake single-access (uniportal) video-assisted thoracoscopic surgery for peripheral pulmonary nodules in a complete ambulatory setting. Ann Thorac Surg 2010; 89: $1625-7$.

3) Gonzalez D, Paradela M, Garcia J, et al. Single-port video-assisted thoracoscopic lobectomy. Interact Cardiovasc Thorac Surg 2011; 12: 514-5.
4) Jutley RS, Khalil MW, Rocco G. Uniportal vs standard three-port VATS technique for spontaneous pneumothorax: comparison of post-operative pain and residual paraesthesia. Eur J Cardiothorac Surg 2005; 28: 43-6.

5) Rocco G. One-port (uniportal) video-assisted thoracic surgical resections-a clear advance. J Thorac Cardiovasc Surg 2012; 144: S27-31.

6) Wurnig PN, Lackner $\mathrm{H}$, Teiner $\mathrm{C}$, et al. Is intercostal block for pain management in thoracic surgery more successful than epidural anaesthesia? Eur J Cardiothorac Surg 2002; 21: 1115-9.

7) Salati M, Brunelli A, Xiumè F, et al. Uniportal videoassisted thoracic surgery for primary spontaneous pneumothorax: clinical and economic analysis in comparison to the traditional approach. Interact Cardiovasc Thorac Surg 2008; 7: 63-6.

8) Hirai K, Takeuchi S, Usuda J. Single-incision thoracoscopic surgery and conventional video-assisted thoracoscopic surgery: a retrospective comparative study of perioperative clinical outcomes. Eur J Cardiothorac Surg 2016; 49 Suppl 1: i37-41.

9) Bertolaccini L, Batirel H, Brunelli A, et al. Uniportal video-assisted thoracic surgery lobectomy: a consensus report from the Uniportal VATS Interest Group (UVIG) of the European Society of Thoracic Surgeons (ESTS). Eur J Cardiothorac Surg 2019; 56: 224-9. 